\title{
Carotid Angioplasty In Octogenarians: A Mono-Arm Trial With Clinical And Angiographic Follow Up
}

\author{
Ehsan Sharifipour ${ }^{1}$, Reza M ohammadian ${ }^{2}$ \\ ${ }^{1}$ Neurology Department, Neurology and Neurosciences Research Center, Qum University of M edical Sciences, \\ Qum,Iran. \\ ${ }^{2}$ Neuroscience Research Center ,Tabriz University of Medical Sciences, Tabriz, Iran.
}

\begin{abstract}
Background: Octogenarians account for a third of ischemic stroke (IS) patients and they have higher morbidity and mortality rate among IS patients. The aim of this study was to evaluate the priprocedural and long term clinical and angiographic statement of carotid artery angioplasty (CAA) in octogenarians.
\end{abstract}

Methods: In a mono-arm trial 102 patients $>80$ years old with symptomatic internal carotid artery (ICA) stenosis presented by non-disabling IS or TIA underwent the CAA and were evaluated prospectively from January 2010 to July 2014. All patients had standard stroke care during the study follow up. The peri-procedural complications, cerebrovascular accidents, restenosis in target vessel and mortality rate were recorded to evaluate safety and durability of this secondary stroke prevention method in octogenarians.

Results: 48 (47.06\%) males and 54 (52.9\%) females in a mean period of 24.5 \pm 14.1 (6-50 months) were followed. For all patients mean age was $83.39 \pm 2.53$ (range, 80-88) years. The success rate of CAA was $100 \%$, whereas the peri-procedural complication rate was $5.8 \%$ (access-site local hematoma and bradycardia during CAA both in 2.94\%). There was only one patient who had acute ischemic stroke during the procedure. Restenosis occurred in 3.9\% after a mean of 21.5 months. The proportion of recurrent cerebrovascular accident was $9.8 \%$ while TIAs occurred in $3.9 \%$ and stroke in $1 \%$ of patients. Also $4.9 \%$ of patients experienced coronary artery disease and the proportion of fatal recurrent cerebrovascular accident was $2.9 \%$. The median patient event-free survival was 20 months.

Conclusion: CAA seems to be a safe and durable IS secondary prevention method in octogenarians with symptomatic carotid artery stenosis.

Key words: Octogenarian; symptomatic carotid artery stenosis; carotid artery Angioplasty

DOI: $10.7575 /$ aiac.abcmed.ca1.64

Published Date: February 2017

Peer-review is under responsibility of the 9th Iranian Stroke Congress.

Published by Australian International Academic Centre, Australia

This published work is open access under the CC BY license.

Available online at www.abcmed.aiac.org.au 